\title{
Left Posterior Basal Transition Zone of Prostate
}

National Cancer Institute

\section{Source}

National Cancer Institute. Left Posterior Basal Transition Zone of Prostate. NCI

Thesaurus. Code C128590.

The region of the prostate that is located on the anatomical left side of the posterior portion of the basal division of the transition zone. 